\title{
Impact of Disintegration Practices and Innovation on the Levels of Integration and Performance of the Supply Chain: Case of Automotive Companies in Morocco
}

\author{
AZDOD Mohamed*, OUABOUCH Hassan \\ Sultan Moulay Slimane University, Laboratory For Studies And Research In Economics And Management \\ «Laboratoire des Études et desRecherchesen Sciences Economiques et de Gestion : LERSEG », BENI MELLAL \\ - MOROCCO

\begin{abstract}
*Corresponding Authors: AZDOD Mohamed, Sultan Moulay Slimane University, Laboratory For Studies And Research In Economics And Management «Laboratoire des Études et desRecherchesen Sciences Economiques et de Gestion : LERSEG», BENI MELLAL - MOROCCO
\end{abstract}

\begin{abstract}
This study extends the developing body of literature on supply chain integration (SCI), which is the degree to which a manufacturer strategically collaborates with its supply chain partners, in order to increase the supply chain performance (SCP) and provide value to consumer. We study the relationship between four dimensions of SCI (Internal, supplier, costumer and provider integration) and the SCP. In addition, we study the interactions between disintegration (outsourcing) and oriented-innovation (Managerial innovation and/or technical innovation) and their effects on performance.
\end{abstract}

A path analysis (structural equation modeling) was used to examine the relationship between all variables. Furthermore, the results indicated that SCI was more strongly related to improving performance than disintegration or oriented-innovation.

Key words: Supply chain integration - Disintegration - Innovation - Supply chain performance

\section{INTRODUCTION}

The automotive industry has become one of the recent success vector of the Moroccan Economy. It can be justified by the increasing number of automotive suppliers and manufacturer on Moroccan territory during the last teen years. It is important to underline the fact that the automotive industry has been the core sector of innovation in management and strategies. In our case, we face the need of improving firm performance in a supply chain environment.

However, this sector is facing serious pressures in terms of costs reduction from both parts: shareholders and customers. Customers aim to get good products in term of quality, prices and delivery time. The main objective here is to reduce manufacturing costs while bringing maximum value to customers.

Based on those elements, several questions can be raised: how can an automotive manufacturer improve its performance (good quality, optimized resources, zero delay)? Many works tried to define the perfect way to achieve that goal: Inventory reduction (Takim, 2014), supply chain integration (Flynn and al., 2010), (lii, 2016), etc.

In this paper, we suggest the integration as a tool to achieve that goal. However, we added some other strategies to studies their synergy with the supply chain integration strategy. In fact, we will focus on the disintegration and innovation strategies as a prerequisite to meet the market and the shareholders needs by insuring the firm performance.

A case study was conducted within a manufacturing plant operating in the different automotive industries in order to explore the possibility of combining innovation, disintegration and supply chain integration to boost core competitiveness of automotive industries, to reduce delivery time, costs and, thus, to enhance firm performance. 
Impact of Disintegration Practices and Innovation on the Levels of Integration and Performance of the Supply Chain: Case of Automotive Companies in Morocco

\section{THEORETICAL BACKGROUND}

\subsection{Innovation Orientation}

According to Siguaw (2006), innovation orientation is a learning philosophy with common standards and beliefs about learning and knowledge that guide firms toward innovation. We can talk about a common mission and promoting a climate of participation in the proposal of new ideas to stimulate creativity. The main objective of the innovation-oriented enterprises is to achieve market success with products and services which satisfy their customers' needs and enhance their loyalty by cultivating a favorable impression and long-term customer relationships.

If the organization stimulates the innovation-oriented climate within it departments, as a strategic orientation, that can positively impact the organizational innovation (Zhou and al., 2005). Moreover, and based on Ngo and O'cass (2011) study, innovation-oriented enterprises look for technological breakthroughs to create value in order to retain actual customers, attract new ones and go beyond their expectations of product or/and service.

The advantage of the innovation orientation relationship, as a strategic orientation, is that it tends to be more internally focused (unlike strategy-oriented relationship for example) and, consequently, it emphasizes the purpose of research and development department. In an integration perspective, it absorbs new technology from the upstream suppliers and learn new knowledge quickly in order to gain core technology competences (Lii and Kuo, 2015).

We believe that the innovation-orientated enterprises focus their efforts on technical and managerial innovations. As a matter of facts, this study suggests that the Moroccan reality of automotive industries combine those two types of innovation to develop innovative products and, in supply chain perspective, to enable a partners' supply (integrated or not) to be more performant than the competitors. This leads us to infer that, on one hand, the adoption of a technical and managerial innovations enhances supply chain integration, on the other hand, it improves supply chain performance.

Therefore, the following hypotheses related to innovation (technical and managerial) may be proposed:

H1. Firms with a strong technical innovation are more likely to integrate their supply chain partners

H2. Firms with strong managerial innovation are more likely to integrate the supply chain partners

H3. Firms with strong technical innovation are more likely to improve the supply chain performance

H4. Firms with strong managerial innovation are more likely to improve the supply chain performance

\subsection{Value Chain Disintegration}

Hence, disintegration allows a dissociation of an activity that creates value. Consequently, the whole Supply Chain of the firm is being reconfigured. Disintegration is a strategy that « consists of deeply restructuring Supply Chains » and leads to formalizing sustainable contractual relationships with partners who have competencies and complementary resources to those available in the organization that disintegrates some of its activities. (Fulconis, et al., 2011).

A practice such as externalization is obviously meant to be reinforced by reliable fundaments. On one side, externalizing enables the firm to be more specialized in its core business. This allows, thanks to gaining experience and skills, creating more value to the shareholders (Quinn \&Hilmer, 1994). On the other side, the expertise of service providers in different domains along with shortening lifecycles incite firms to externalize some activities (Desreumaux, 1996).

Barthélémy\&Donada (2007) state that a disintegration decision may be justified by three complementary approaches:

— The approach « competencies-resources »: When a firm suffers from a lack of competencies required to execute an internal activity. This guarantees a better productivity internally as well as externally (focusing on the core business); 
— The approach «flexibility »: By disintegrating, the internal organizational structure is improved, and the firm becomes more flexible and reactive. This enables the organization to optimize the different organizational aspects (delays minimization, processes enhancement, etc.);

- The approach « opportunism »: Unlike the previous approach (flexibility), this one postulates that a disintegration decision should not be adopted if the partner is placed in a dependency situation which is disadvantageous and asymmetric.

The approach «flexibility » induces us to suppose that disintegration may promote innovative practices. However, the " competencies-resources » and «flexibility » lead us to assume that disintegration may promote the SCP. Thus, we suggest the following hypotheses:

\section{H5. Disintegration promotes technical innovation}

\section{H6. Disintegration promotes managerial innovation}

\section{H7. Disintegration promotes the SCP}

\subsection{Supply Chain Integration}

The supply chain integration can be defined as the level of commitment with suppliers and customers (Frohlich and Westbrook, 2001). The authors have tried to develop a new way of characterizing the direction and degree of supply chain integration by considering upstream supplier and downstream customer integration during their analysis.

The integration, in the supply chain context, involves the collaboration between stakeholders and cross-organizational processes ( $\mathrm{Lii}$ and Kuo, 2016). The main goal is to insure effectiveness and efficiency in decisions making concerning products, services, information, capital, costs reduction and so on.

From the foregoing, the supply chain integration can be summed up in two types: external and internal integration. Concerning the external integration, many authors as Flynn (2010) suggest that suppliers, customers and even the providers are the main involved actors of this category. From one hand, suppliers and providers, as the main actors of the backward external integration, in an integration strategy, may assist the manufacturers to develop new materials, produce innovative ideas during the design and development of new products for example.

From the other hand, the forward external integration is represented by the integrated customers. This type of integration involves logistics information flow and services, and proceeds from information provided by customers to the supplier (Lii and Kuo, 2016).

Therefore, the internal integration refers to a cross-functional strategy system and to a responsibility for cross-functional collaboration. Whether internal or external integration, the supply chain integration seeks for providing maximum value to customers in the shortest time. Thus, we suggest:

\section{H8. Supply chain integration promotes the SCP}

\section{Methodology, Hypotheses And Preliminary Model}

This paper aims, on one hand, to verify the impact of innovation when it comes to applying practices of logistics integration according to different levels, on the other hand, to corroborate the impact of logistics integration on the SCP. As for disintegration, it helps promoting the organization's performance and maintaining causal relationships with innovation practices. In our case, we are going to consider multinational industrial firms based in Morocco and compare their logistics integration degrees, more specifically information systems, in terms of the «SCP ».

Our investigation method is based on an interview guide deployed among logistics employees and those responsible for planning process of multinational firms operating in the automotive industry in Morocco, along with managers of logistics departments who have a global vision on organizational performance in terms of logistics. Some of these firms have an integrated information system, while the other ones opt for the classic functioning of EDI (exchange of the electronic message through a classic e-mail account and an Excel file or a universal spreadsheet).

The choice of the sampling frame can be justified by the fact that this sector is framed by the national plan of the industrial acceleration (2014-2020) that recommends the logic of industrial ecosystems 
Impact of Disintegration Practices and Innovation on the Levels of Integration and Performance of the Supply Chain: Case of Automotive Companies in Morocco

and the implementation of an integrated industry. This involves the existence of disintegration and logistics integration practices. The presence of these activities enables this sector to be a perfect study field to test our research model.

The methodology is based on a hypothetico-deductivemethod: firstly, we have developed our model by abduction before testing and corroborating the hypothesesthanks to our survey. For now, we are going to decompose the research problem into measurable elements representing the main object of an interview guide based on 96 firms operating in the automotive and wiring industry in Morocco.

The first analysis concerns reducing dimensions and has been made to extract the most significant component for each section of the questionnaire. Tests results Kaiser-Meyer-Olkin show a minimum value of 0,685 out of the 7 sections of the questionnaire. It is important to point out that a value of 0,50 is necessary before proceeding to a reduction of dimensions. Therefore, scores about 0,70 are considered as very reliable. The extraction has been made through the Anderson-Rubin method; which guarantees that the scores obtained are standardized (a zero mean and a unitary standard deviation).

Hence, a score may be assigned to each firm in order to measure the degree of innovation, the degree of integration, the degree of disintegration or even the degree of the SCP. These factorial scores are going to be used later on to test the hypotheses. It is necessary to note that all the coefficients of Cronbach's Alpha exceed 0,822; which reflects a good reliability of the measurement scale used (Table 1).

\begin{tabular}{|c|c|}
\hline Section of the survey & Cronbach's Alpha coefficient \\
\hline Innovation & 0,822 \\
\hline Internal integration & 0,973 \\
\hline Supplier integration & 0,976 \\
\hline Customer integration & 0,974 \\
\hline Providers integration & 0,925 \\
\hline Disintegration & 0,891 \\
\hline SCP & 0,901 \\
\hline
\end{tabular}

Table1. Descriptive and reliability analysis

Based on Flynn et al. (2010) and Lii et al. (2016) works along with some modifications, the SCI is represented by 4 sub-variables: an internal integration, a suppliers' integration, a customers' integration and a providers' integration. The analysis of dimensions' reduction related to factorial scores of the 4 sections of the SCI enabled us to extract a single factor (which illustrates the global level of the SCI) with an eigenvalue of 3,491 out of 4 .

\section{Total Variance Explained}

\begin{tabular}{lr|r|r|r|r|r} 
& \multicolumn{3}{c|}{ Initial Eigenvalues } & \multicolumn{3}{c}{ Extraction Sums of Squared Loadings } \\
Component & Total & \% of Variance & Cumulative \% & Total & \% of Variance & Cumulative \% \\
\hline 1 & 3,491 & 87,282 & 87,282 & 3,491 & 87,282 & 87,282 \\
\hline 2 &, 464 & 11,603 & 98,885 & & & \\
\hline 3 &, 034 &, 841 & 99,726 & & & \\
\hline 4 &, 011 &, 274 & 100,000 & & & \\
\hline \multicolumn{5}{|l|}{ Extraction Method: Principal Component Analysis. }
\end{tabular}

Table2. Extraction of the latent variable (Supply Chain Integration)

The analysis of the answers obtained thanks to the questionnaire related to the «Innovation » section through the principal component analysis (PCA) allowed us to extract two components. By analyzing the items' correlation with each component, we may admit that the first component is linked to innovation seen from its managerial aspect (introduction of new managerial practices), while the second component concerns pure technological practices. Eventually, these two components are independent and there is no correlation or causal relationship between the two of them. 


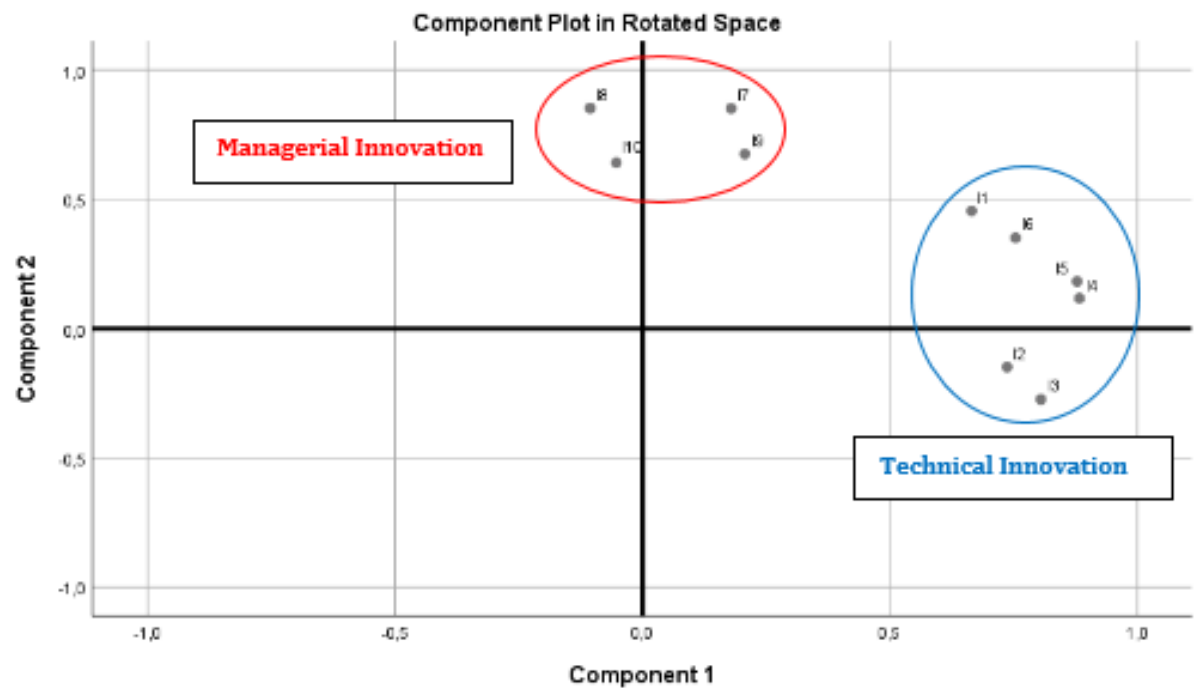

Figure1. Factorial chart of innovation components

These innovation practices are supposed to allow a better logistics integration or, if necessary, directly impact the SCP. For this purpose, we may formulate the following fourhypotheses:

\section{H-1: Technical innovation allows increasing the degree of the SCI}

\section{H-2: Managerial innovation allows increasing the degree of the SCI}

\section{H-3: Technical innovation allows improving the SCP}

\section{H-4: Managerial innovation allows improving the SCP}

Otherwise, disintegration activities may encourage the organization to adopt innovative practices in order to standardize processes, information systems or managerial practices with service providers. These practices may also represent a source for the SCP improvement (better organization, flexible structures, etc.). Thus, three new hypothesesmay be defined:

\section{H-5: Disintegration promotes technical innovation}

\section{H-6: Disintegration promotes managerial innovation}

\section{H-7: Disintegration promotes the SCP}

Finally, SCI practices are supposed to enhance the SCP through delays minimization and service rate improvement:

\section{H-8: Logistics integration promotes the SCP}

Therefore, our initial research model is going to be represented as follows:

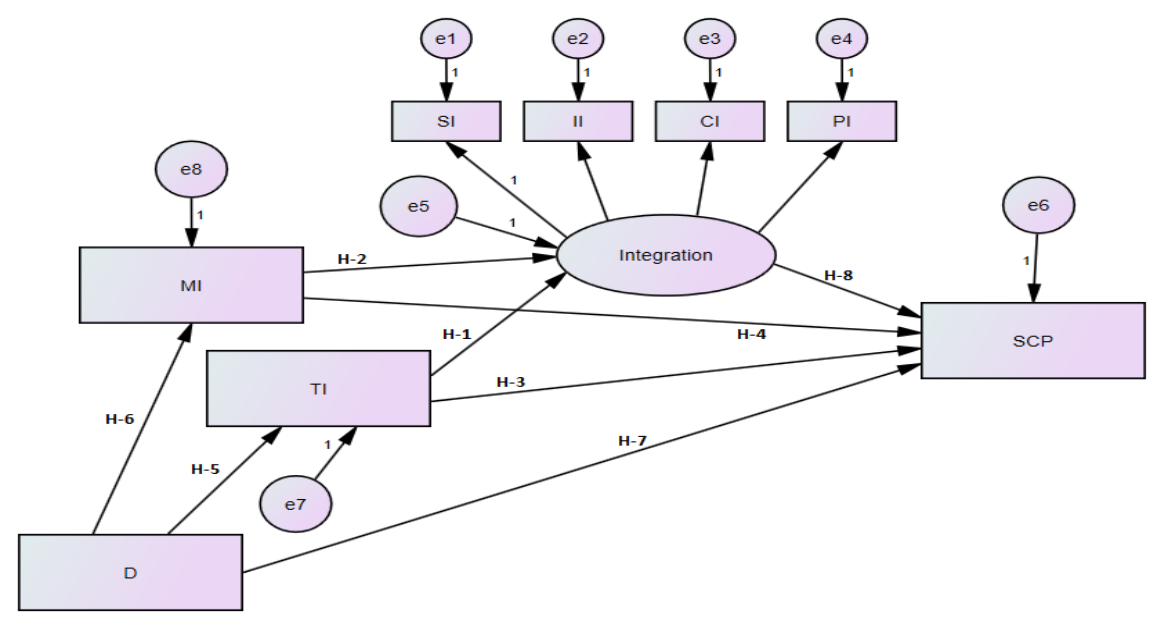

Figure2. Initial research model 


\section{Results}

At this stage, the hypothesesshould be tested. For this purpose, a structural equation modeling has been made. In fact, the first analysis has provided the following results:

Regression Weights: (Group number 1 - Default model)

\begin{tabular}{|c|c|c|c|c|c|c|}
\hline & & Estimate & S.E. & C.R. & P & Label \\
\hline $\mathrm{TI}$ & $<---D$ & .322 & ,097 & 3,314 & $* * *$ & par_9 \\
\hline MI & $<-\infty D$ &, 184 &, 101 & 1,828 &, 067 & par_10 \\
\hline Integration & $<-.-\quad$ MI &, 171 &, 082 & 2,085 & 037 & par_5 \\
\hline Integration & $<-.-$ TI &, 579 &, 082 & 7,062 & $* * *$ & par_6 \\
\hline SI & $<--$ Integration & 1,000 & & & & \\
\hline II & $<--$ Integration &, 982 & .021 & 45,674 & $* * *$ & par_1 \\
\hline PI & $<--$ Integration &, 675 & ,076 & 8,908 & $* * *$ & par_2 \\
\hline SCP & $<---$ Integration &, 568 & ,070 & 8,103 & $* * *$ & par_3 \\
\hline $\mathrm{CI}$ & $<--$ Integration & ,991 &, 017 & 58,993 & $* * *$ & par_4 \\
\hline SCP & $<---$ TI & 244 &, 071 & 3,419 & $* * *$ & par_7 \\
\hline SCP & $<--D$ & 215 &, 060 & 3,602 & $* * *$ & par_8 \\
\hline SCP & $<\ldots \quad$ MI &, 068 &, 058 & 1,170 &, 242 & par_11 \\
\hline
\end{tabular}

Table3. Results of the initial model validation

It is relevant to point out that among all the hypotheses that have been formulated, we may refute the existence of a causal relationship between disintegration and managerial innovation (Hypothesis H6) or even a causal relationship between managerial innovation and the SCP (Hypothesis H4). After adjusting our model by eliminating these two refuted relations, a new analysis by structural equations has provided the following standardized coefficients:

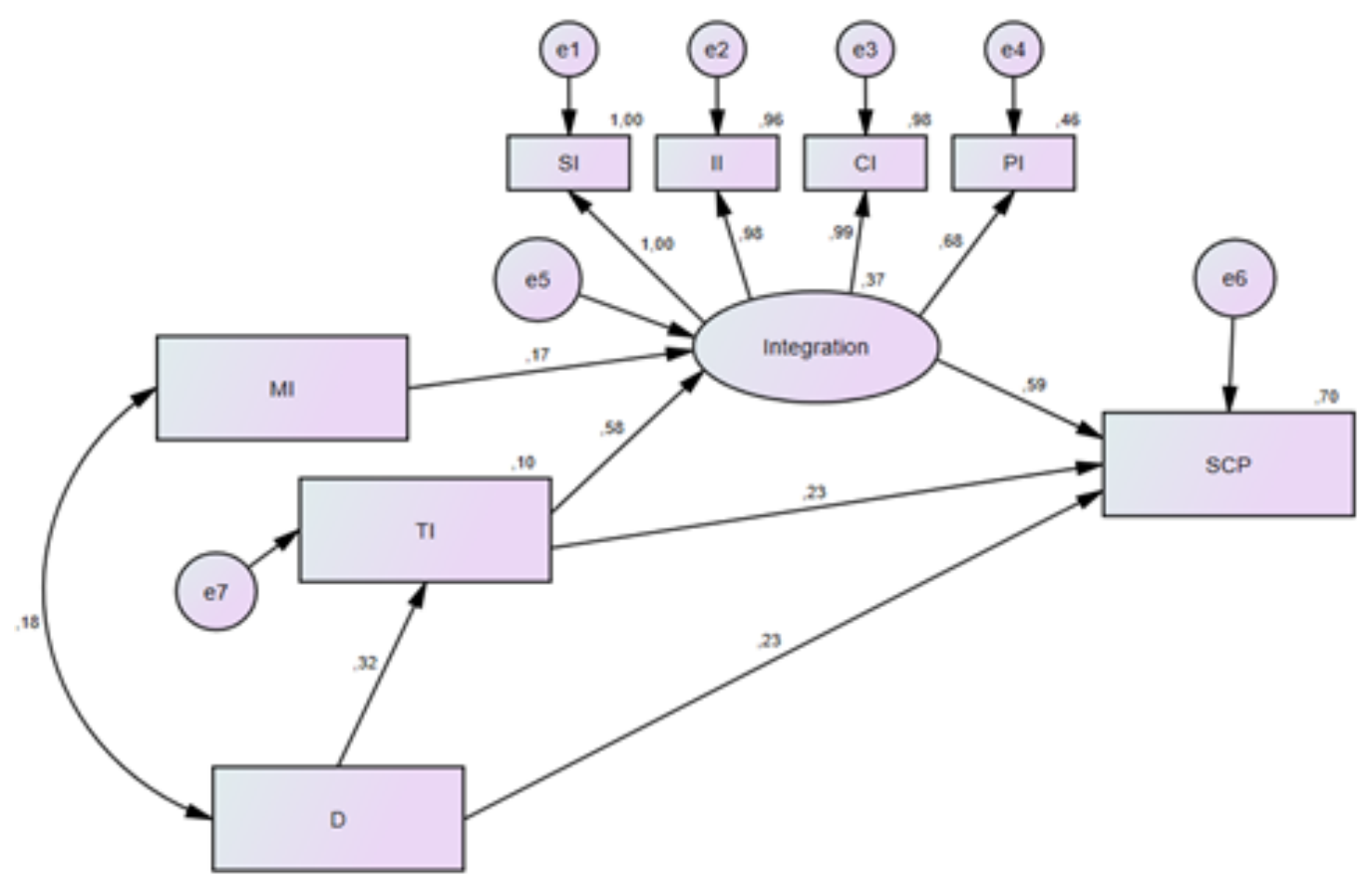

Figure3. Adjusted research model

As shown in the following table representing regression coefficients, all the hypotheses are supported and very significant $(\boldsymbol{p}$-value $\mathbf{0} \mathbf{0 , 0 5})$. Indeed, the good quality of the factorial analysis of the latent variable « Integration » which contains 4 integration sub-variables has been noticed. Once our model is adjusted and corroborated, we are going to discuss the interpretations of these results and also the quality of our modeling. 
Regression Weights: (Group number 1 - Default model)

\begin{tabular}{lll|rrrrr} 
& & & Estimate & S.E. & C.R. & P & Label \\
II & $<---$ & D &, 322 &, 097 & 3,314 & $* * *$ & par_9 \\
Integration & $<---$ & MI &, 171 &, 082 & 2,091 &, 037 & par_5 \\
\hline Integration & $<---$ & TI &, 579 &, 082 & 7,063 & $* * *$ & par_6 \\
SI & $<---$ & Integration & 1,000 & & & & \\
II & $<---$ & Integration &, 982 &, 022 & 45,624 & $* * *$ & par_1 \\
PI & $<---$ & Integration &, 675 &, 076 & 8,908 & $* * *$ & par_2 \\
SCP & $<---$ & Integration &, 584 &, 069 & 8,457 & $* * *$ & par_3 \\
CI & $<---$ & Integration &, 991 &, 017 & 59,036 & $* * *$ & par_4 \\
SCP & $<---$ & TI &, 230 &, 071 & 3,232 &, 001 & par_7 \\
SCP & $<---$ & D &, 227 &, 059 & 3,840 & $* * *$ & par_8
\end{tabular}

Table4. Results of the adjusted model validation

\section{DISCUSSION AND EMPIRICAL INTERPRETATION}

Based on the statistical tests that have been made, we have concluded that innovation, seen from its managerial aspect, does not impact the SCP and presents a very weak effect on the implementation of the SCI, unlike the technical practices of innovation (for a direct standardized effect of 0,58 against only 0,17 ). As a matter of fact, this means that in the automotive and wiring industry in Morocco, innovation practices that promote logistics performance are especially those that are technological. In practice, the automotive industry is considered as a very disintegrated sector; which means that practices of the technical innovation allow the implementation of new solutions in terms of information systems.

This impact of the technical innovation on the SCP passes mainly through logistics integration. The direct standardized effect of the technical innovation on logistics integration reaches an estimated value of 0,576 . Considered as a mediator variable, the SCI impacts positively the SCP with a direct standardized effect of 0,588 .

The indirect standardized effect of the technical innovation practices on the SCP reaches 0,339. Eventually, these practices do not impact the SCP only through logistics integration mediation; other mediator or moderator variables may be considered (such as productivity or staff training for example). The direct effect which summarizes these interactions is estimated at 0,231 . In general, an effect of 0,57 is considered between the two variables (technical innovation and the SCP). We note that the indirect effect is significantly higher than the direct effect; this shows that mediation is very significant and has a great causal intensity.

In fact, disintegration practices impact moderately the SCP. The Moroccan automotive industry is characterized by a high intensity of integration (less than $10 \%$ of the main firms in the Supply Chains). These effects may be illustrated by a better costs control (transformation of fixed costs into variable costs) or even the lightening of complex structures that take advantage from flexibility and experience. The direct standardized effect reaches an estimated value of 0,22 . These practices, such as externalization or sub-contracting, force some firms to use more innovative information systems.

Indeed, technical innovation is caused, up to $10 \%$, by disintegration practices. These activities are likely to impact indirectly the SCP, whether by technical innovation mediation or the simultaneous mediation of technical innovation and the SCI by a standardized coefficient of 0,183 .

The SCI impacts very positively the SCP thanks to the minimization of delays, the optimization of stocks levels, the synchronization of data in real time, etc. The related direct standardized effect reaches 0,588 . This means that when the degree of the SCI increases by a single standard deviation, the performance of the chain raises consequently by 0,588 standard deviation. 
Impact of Disintegration Practices and Innovation on the Levels of Integration and Performance of the Supply Chain: Case of Automotive Companies in Morocco

Standardized Total Effects (Group number l - Default mo
\begin{tabular}{|l|rrrr|}
\hline \multicolumn{1}{|c|}{} & D & MI & TI & Integration \\
\hline TI &, 322 &, 000 &, 000 &, 000 \\
Integration &, 186 &, 171 &, 576 &, 000 \\
SCP &, 411 &, 100 &, 570 &, 588 \\
PI &, 125 &, 115 &, 390 &, 676 \\
CI &, 184 &, 169 &, 570 &, 989 \\
II &, 182 &, 167 &, 565 &, 980 \\
SI &, 185 &, 170 &, 575 &, 998 \\
\hline
\end{tabular}

Table5. Total effects of the adjusted model

Standardized Direct Effects (Group number 1 - Default model)

\begin{tabular}{l|rrrr} 
& D & MI & TI & Integration \\
TI &, 322 &, 000 &, 000 &, 000 \\
Integration &, 000 &, 171 &, 576 &, 000 \\
SCP &, 228 &, 000 &, 231 &, 588 \\
PI &, 000 &, 000 &, 000 &, 676 \\
CI &, 000 &, 000 &, 000 &, 989 \\
II &, 000 &, 000 &, 000 &, 980 \\
SI &, 000 &, 000 &, 000 &, 998
\end{tabular}

Standardized Indirect Effects (Group number 1 - Default model)

\begin{tabular}{|l|rrrr|} 
& D & MI & TI & Integration \\
\hline TI &, 000 &, 000 &, 000 &, 000 \\
Integration &, 186 &, 000 &, 000 &, 000 \\
SCP &, 183 &, 100 &, 339 &, 000 \\
PI &, 125 &, 115 &, 390 &, 000 \\
CI &, 184 &, 169 &, 570 &, 000 \\
II &, 182 &, 167 &, 565 &, 000 \\
SI &, 185 &, 170 &, 575 &, 000 \\
\hline
\end{tabular}

Table6. Direct and indirect effects of the adjusted model

Once the local quality of the model has been verified, it is relevant to appreciate its global quality. On this basis, 11 iterations have been made. The model contains 16 variables including 8 latent variables. Among all the variables, 7 are endogenous variables while 9 variables are exogenous.

The value of the Chi-Square obtained is 58,638 , with a p-value of 0.000 (highly significant). The score of the SCP has reached $70 \%$. The indexes GFI and CFI indicate respectively values of 0,875 and 0,954 , remaining fairly close to 1 and confirming a very acceptable quality of the modeling. Nonetheless, the index RMSEA presents a value of 0,145 which remains higher than 0,08 . However, this may be explained by the multiple square correlation of the variable «Technical innovation » which represents only 0,104 .

\section{Conclusion And Perspectives}

In this paper, we have demonstrated the importance of the technical innovation practices when it comes to upgrading the organizational performance, whether it is directly or through mediation. The importance of disintegration practices (such as externalization, sub-contracting, etc.) in improving performance remains fairly average. Effectively, the enhancement of the performance does not reflect the first motivation for firms operating in the automotive industry when it concerns disintegration.

The studied Supply Chains in this sector are nonlinear chains: they are more like chains within the same network in which the manufacturer has the most relevant role. The limited inter-organizational integration stills sufficiently high with a minor advantage upstream (supplier integration remains the most advanced form of integration). Providers integration, compared to the other sections, is being fairly average and this may be explained by the size of these firms in which, most of them, are small and medium-sized enterprises (SMEs).

This research represents an opportunity for researchers and firms to dig a little more for the nature of the relationship between integration, disintegration activities and innovation practices. Certainly, we are aware of the multitude of variables that may influence, on one hand, the decision of disintegrating or not (costs, feasibility, providers availability, quality of the services provided, etc.). On the other hand, the decision of pushing thoroughly the degree of integration with stakeholders and considering all the risks that may be generated (financial resources, risk of sharing confidential information, risk of competitive imbalance, etc.), along with the establishment of innovative practices that are generally resulting from training effects. 
This study aims essentially the Moroccan automotive and wiring industry; a sector known by its practices of disintegration. Furthermore, it is important to contextualize the study in its spatiotemporal frame: the structural deficit from which the commercial balance of goods suffers, combined with the willingness of the Moroccan Government to maintain this sector as the first national exporter, make this industry more particular and unique compared to the other sectors. All the previous data hinder the possibility of inferring the results obtained on the other organizations in Morocco or even on the other business sectors.

\section{REFERENCES}

[1] Azdod, M., Acharki, H., Bakhat, R. \& Rajaa, M., 2017. Impact of innovation on the supply chain performance: Case of the automotive industry in Morocco. European Journal of Logistics, Purchasing and Supply Chain Management, February, 05(01), pp. 1-21.

[2] Barratt, M., 2004. Understanding the meaning of collaboration in the supply chain. Supply Chain Management: An International Journal, 9(1), pp. 30-42.

[3] Barthélemy, J., 2009. Externalisation : le manque de contrat tue; l'excès aussi. L'Expansion Management Review, Avril, Issue 135, p. 122 à 127.

[4] Barthélémy, J. \& Donada, C., 2007. Décision et gestion de l'externalisation : une approche intégrée. Revue française de gestion, August, Issue 177, pp. 101-111.

[5] Bask, A. \& Juga, J., 2001. Semi-Integrated Supply Chains: Towards the New Era of Supply Chain Management. International Journal of Logistics, July, 4(2), pp. 137-152.

[6] Christopher, M. \& Juttner, U., 2000. Supply Chain Relationships: Making the Transition to Closer Integration,. International Journal of Logistics Research and Applications, 3 (1) 5-23., 3(1), pp. 5-23.

[7] Desreumaux, A., 1996. Nouvelles formes d'organisation et évolution de l'entreprise. Revue Française de Gestion, January-February, pp. 86-108.

[8] Fabbe-Costes, N., 2007. La gestion des chaînes logistiques multi-acteurs : les dimensions organisationnelles d'une gestion lean et agile. Dans: La gestion des chaînes logistiques multi-acteurs : perspectives stratégiques. Grenoble: Presses Universitaires de Grenoble, pp. 19-43.

[9] Fawcett, S. E. \& Magnan, G. M., 2002. The rhetoric and reality of supply chain integration. International Journal of Physical Distribution \& Logistics Management, 32(5), pp. 339-361.

[10] Fenneteau, H. \& Naro, G., 2005. Contrôle et confiance dans l'entreprise virtuelle : Illustrations logistiques. Revue française de gestion, Mars, Issue 156, pp. 203-219.

[11] Flynn, B. B., Huo, B. \& Zhao, X., 2010. The impact of supply chain integration on performance: A contingency and configuration approach. Journal of Operations Management, Janvier, 28(1), pp. 58-71.

[12] Frohlich, M. \& Westbrook, R., 2001. Arcs of Integration: An International Study of Supply Chain Strategies. Journal of Operations Management, 19(2), pp. 185-200.

[13] Garrouche, K., Mzoughi, N., Ben Slimane, I. \& and Bouhlel, O., 2011. An Investigation into the Consumers : Sensitivity of the Logistics Efficiency. International Journal of Business Administration, 2(2), pp. 114-128.

[14] Handfielda, R. B. \& Bechtelb, C., 2002. The role of trust and relationship structure in improving supply chain responsiveness. Industrial Marketing Management, Issue 31, pp. 367-382.

[15] Harland, C. \& Knight, L., 2000. Supply network strategy: Role and competence requirements. International Journal of Operations \& Production Management, 21(4), pp. 476-489.

[16] Jahre, M. \& Fabbe-Costes, N., 2005. Adaptation and adaptability in logistics networks. International Journal of Logistics Research and Applications: A Leading Journal of Supply Chain Management, 8(2), pp. 143-157.

[17] Jain, A. \& Thiétart, R.-A., 2007. Dynamique concurrentielle et cascades d'externalisations. Revue française de gestion, Aout, Issue 177, pp. 149-162.

[18] Kemppainen, K. \& Vepsäläinen, A. P., 2003. Trends in industrial supply chains and networks. International Journal of Physical Distribution \& Logistics Management, 33(8), pp. 701-719.

[19] Lii, P. \& Kuo, F.-I., 2016. Innovation-oriented supply chain integration for combined competitiveness and firm performance. International Journal of Production Economics, Avril, 174(C), pp. 142-155.

[20] Mentzer, J. T. et al., 2001. Defining Supply Chain Management. Journal of business logistics, 22(2), pp. 125.

[21] Nakhla, M., 2006. Supply Chain Management et performance de l'entreprise "Value Based Supply Chain Management Model". Logistique \& Management, 14(1), pp. 65-77. 
Impact of Disintegration Practices and Innovation on the Levels of Integration and Performance of the Supply Chain: Case of Automotive Companies in Morocco

[22] Piccoli, G., 2012. Information systems for managers : text \& cases. 2e éd. s.1.:Hoboken, N.J. Wiley, [2012].

[23] Prajogo, D. \& Olhager, J., 2012. Supply chain integration and performance: The effects of long-term relationships, information technology and sharing, and logistics integration. International Journal of Production Economics, 135(1), pp. 514-522.

[24] Ryssel, R., Ritter, T. \& Gemünden, H., 2004. The impact of information technology deployment on trust, commitment and value creation in business relationships,. The Journal of Business and Industrial Marketing, 19(3), pp. 197-207.

[25] Skjott-Larsen, T. \& Bagchi, P., 2002. Challenges of Integration in Supply Chain Networks: An European Case Study. ACES Working Paper, Août, pp. 1-49.

[26] Takim, S. A., 2014. Optimization of effective inventory contorl and managmeent in manufacturing industries: Case study of flour mills company Calabar, Nigeria. Journal of emerging Trends in Engineering and Applied Sciences (JETEAS), 5, 265-276.

[27] Van der Meer-Kooistra, J. \& Vosselman, E., 2000. Management control of interfirm transactional relationships: the case of industrial renovation and maintenance. Accounting, Organizations and Society, Volume 25, pp. 51-77.

[28] Van der Vaart, T. \& Van Donk, D. P., 2008. A critical review of survey-based research in supply chain integration. International Journal of Production Economics, 31 Janvier, 111(1), pp. 42-55.

[29] Véronneau, S., Pasin, F. \& Roy, J., 2008. L'information dans la chaîne logistique. Revue française de gestion, Juin, Issue 186, pp. 149-161.

Citation: AZDOD Mohamed, OUABOUCH Hassan, "Impact of Disintegration Practices and Innovation on the Levels of Integration and Performance of the Supply Chain: Case of Automotive Companies in Morocco" International Journal of Managerial Studies and Research (IJMSR), vol 9, no. 5, 2021, pp. 19-28. doi: https://doi.org/10.20431/2349-0349.0905003.

Copyright: () 2021 Authors. This is an open-access article distributed under the terms of the Creative Commons Attribution License, which permits unrestricted use, distribution, and reproduction in any medium, provided the original author and source are credited. 